\title{
Landslide mapping with multi-scale object-based image analysis - a case study in the Baichi watershed, Taiwan
}

\author{
T. Lahousse ${ }^{1}$, K. T. Chang ${ }^{2}$, and Y. H. Lin ${ }^{3}$ \\ ${ }^{1}$ Department of Geography, National Taiwan University, Taipei, Taiwan \\ ${ }^{2}$ Kainan University, Luzhu, Taoyuan, Taiwan \\ ${ }^{3}$ Geotechnical Engineering Research Center, Sinotech Engineering Consults Inc., Taipei, Taiwan
}

Received: 25 February 2011 - Revised: 6 September 2011 - Accepted: 7 September 2011 - Published: 10 October 2011

\begin{abstract}
We developed a multi-scale OBIA (object-based image analysis) landslide detection technique to map shallow landslides in the Baichi watershed, Taiwan, after the 2004 Typhoon Aere event. Our semi-automated detection method selected multiple scales through landslide size statistics analysis for successive classification rounds. The detection performance achieved a modified success rate (MSR) of $86.5 \%$ with the training dataset and $86 \%$ with the validation dataset. This performance level was due to the multi-scale aspect of our methodology, as the MSR for single scale classification was substantially lower, even after spectral difference segmentation, with a maximum of $74 \%$. Our multi-scale technique was capable of detecting landslides of varying sizes, including very small landslides, up to $95 \mathrm{~m}^{2}$. The method presented certain limitations: the thresholds we established for classification were specific to the study area, to the landslide type in the study area, and to the spectral characteristics of the satellite image. Because updating site-specific and image-specific classification thresholds is easy with OBIA software, our multi-scale technique is expected to be useful for mapping shallow landslides at watershed level.
\end{abstract}

\section{Introduction}

Landslide hazard is defined as the probability of occurrence within a specified period of time and within a given area of a potential damaging phenomenon of a given magnitude (Varnes et al., 1984; Guzzetti et al., 1999). To perform a landslide hazard assessment, mapping landslides is essential (Hansen, 1984). Among the different types of landslide maps, landslide inventory maps portray the spatial distribution of known landslides (Guzzetti et al., 1999), as they are

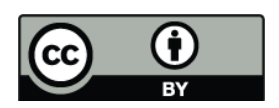

Correspondence to: K. T. Chang (ktchang@ntu.edu.tw) detected and delineated. To map landslide inventories, researchers have traditionally relied on the analysis of aerial photographs, combined with field investigations and the collection of historical information (Guzzetti et al., 2000). However, new techniques have emerged, one of which is the object-based image analysis approach (OBIA) (Martha et al., 2010).

OBIA, commercialized through the Definiens software package, has been widely adopted across the scientific community (Blaschke, 2010). Barlow et al. (2003, 2006), Martin and Franklin (2005), Park and Chi (2008), Moine et al. (2009), Martha et al. (2010, 2011), Lu et al. (2011), and Stumpf and Kerle (2011b) have resorted to OBIA in landslide-related research. OBIA performs both segmentation and classification of an image. Segmentation merges pixels into objects while classification is performed on these objects (Thomas et al., 2003; Benz et al., 2004; Gitas et al., 2004; Walter, 2004). Van Westen et al. (2008) considers that OBIA fares better than pixel-based methods in landslide mapping, precisely because of the grouping of pixels into objects, which decreases the variance of spectral values between landslide objects by averaging the pixels within the object (Zhou et al., 2008). OBIA also benefits from the availability of spatial relations, shape characteristics, and expert knowledge during classification (Zhou and Troy, 2008). We therefore adopted OBIA for a case study of landslide inventory mapping in Xiuluan, in the Baichi watershed, northern Taiwan, following the 2004 Typhoon Aere.

One difficulty with OBIA is the choice of scale for analysis (Dragut et al., 2010). The scale parameter in OBIA is an abstract term which determines the maximum allowed heterogeneity for the resulting image objects (Definiens, 2007). By modifying the value of the scale parameter, the size of image objects varies (Kim et al., 2008). Also, for heterogeneous data, the resulting objects for a given scale parameter will be smaller than those for more homogeneous data. While most research so far has relied on single scales for analysis

Published by Copernicus Publications on behalf of the European Geosciences Union. 
(Blaschke, 2010) or chosen through trial and error (Blaschke and Hay, 2001), Dragut et al. (2010) and Esch (2008) have developed schemes to select and optimize the most appropriate scales for analysis. Recently, Martha et al. (2011) and Stumpf and Kerle (2011a) have also tried to determine scale thresholds for multi-scale analysis of landslides through different statistical approaches. In this study, we also adopted a multi-scale approach for landslide mapping, because landslide size statistics show that landslides occur in different sizes (Malamud et al., 2004; Guzzetti, 2005). We used a landslide size distribution to parameterise the scale parameters and performed a case study, in which a multi-scale OBIA methodology was developed to detect and classify landslides and to produce a complete landslide inventory map, i.e. a landslide inventory map including a substantial fraction of all landslides at all scales (Malamud et al., 2004).

\section{Study area and materials}

\subsection{Study area}

The choice of the study area was driven by the necessity to possess the input data - a satellite image, a digital elevation model (DEM) and a landslide inventory against which to assess the validity of our methodology. We thus selected Xiuluan, the $40 \mathrm{~km}^{2}$ northern section of the $120 \mathrm{~km}^{2}$ Baichi watershed in northern Taiwan, on the west side of the Central Mountain Range (Fig. 1). Baichi is the most upstream section of the Shihmen Reservoir, a strategic resource for all of northern Taiwan (Chiu et al., 2007; Chang and Chiang, 2009).

Geomorphologically, Baichi is representative of mountainous watersheds in Taiwan, with a rugged topography, heavily fractured bedrocks, shallow soils less than $2 \mathrm{~m}$ deep, steep slopes, and frequent landsliding. Elevations range from $830 \mathrm{~m}$ a.s.l. in the northwest to $3320 \mathrm{~m}$ in the southeast. Climatically, Baichi is influenced by typhoons in summer and the northeast monsoon in winter. The mean monthly temperature is $27.5^{\circ} \mathrm{C}$ in July and $14.2^{\circ} \mathrm{C}$ in January, with a mean annual temperature of $21^{\circ} \mathrm{C}$. The annual precipitation averages $2370 \mathrm{~mm}$. Because of typhoons, large rainfall events usually happen from May to September. In this humid environment, coniferous, broadleaf, and bamboo forests thrive and cover most of the watershed. Aboriginal settlements, road networks, agricultural fields, orchards and forest exploitation are concentrated in the eastern part of the watershed.

The study area was divided into 8 sub-watersheds, generated from a DTM in GIS with the hydrology tools. The DTM is described in the following data section. Four of the sub-watersheds were selected to constitute our training area $\left(20.58 \mathrm{~km}^{2}\right)$, and the remaining four were kept for validation $\left(18.87 \mathrm{~km}^{2}\right)$. The partitioning of the sub-watersheds between training and validation areas was done to ensure
Table 1. Landslide inventory data.

\begin{tabular}{llllll}
\hline & $\begin{array}{l}\text { Count } \\
(n)\end{array}$ & $\begin{array}{l}\text { Max } \\
\left(\mathrm{m}^{2}\right)\end{array}$ & $\begin{array}{l}\text { Mean } \\
\left(\mathrm{m}^{2}\right)\end{array}$ & $\begin{array}{l}\text { Min } \\
\left(\mathrm{m}^{2}\right)\end{array}$ & $\begin{array}{l}\text { Stdev } \\
\left(\mathrm{m}^{2}\right)\end{array}$ \\
\hline Training & 97 & 90363 & 2964 & 190 & 9812 \\
Entire Inventory & 190 & 90363 & 2846 & 150 & 6203 \\
\hline
\end{tabular}

both areas were not disproportionate, and contained approximately equal numbers of landslides, and displayed similar geomorphologic conditions and close proportions of natural vs. human-related landuses.

\subsection{Data}

The methodology we developed to detect and map landslides was tested in Xiuluan after the passage of Typhoon Aere. The typhoon struck the area over a three-day period (23-25 August 2004). Through its intense and prolonged rainfall, $1607 \mathrm{~mm}$ of total rainfall recorded over $57 \mathrm{~h}$ and $52.6 \mathrm{~mm} \mathrm{~h}^{-1}$ of maximum 24-h rainfall intensity, Typhoon Aere caused numerous slope failures across the watershed (Chiang and Chang, 2009). According to Rau et al. (2007), Typhoon Aere is the worst typhoon ever to have struck the Shihmen watershed. It caused losses of up to 45.7 million USD and more than 15 fatalities. It also caused an inflow volume 2.83 times greater than the maximum storage capacity for normal operations of the Shihmen Reservoir (Cheng et al., 2008).

We trained and validated our OBIA methodology with a 190 landslide inventory derived from a bilateral research project by the CNR - IRPI (Italian National Research Council - Istituto di Ricerca per la protezione Idrogeologica) (Table 1).

The air-photo interpretation was undertaken with the standard methodology and techniques CNR-IRPI applied in earlier landslide mapping based on aerial photographs (Guzzetti et al., 2006a). It used the pairs of 1:5000 colour aerial photographs taken on 2 September 2004 with a pixel size of $0.35 \mathrm{~m}$ and an estimated horizontal accuracy of $0.5 \mathrm{~m}$, compiled by the Aerial Survey Office of Taiwan's Forestry Bureau. The inventory consisted of 119 shallow slides and 71 debris slides (Fig. 2). It was estimated by the interpreter that 5 slides had a depth of 2 to $10 \mathrm{~m}, 62$ to $5 \mathrm{~m}, 221$ to $2 \mathrm{~m}$, $421 \mathrm{~m}$, and 115 less than $0.5 \mathrm{~m}$.

To detect landslides in the study area after Typhoon Aere, a SPOT-5 image taken on 2 November 2004 was selected. We recognize that the time elapsed between the passage of Typhoon Aere in late August and the moment the satellite image was taken in early November may influence the detection results. Although there was no typhoon between late $\mathrm{Au}-$ gust and early November, smaller precipitations could still have an impact on landslide occurrence. Also, mitigation of 


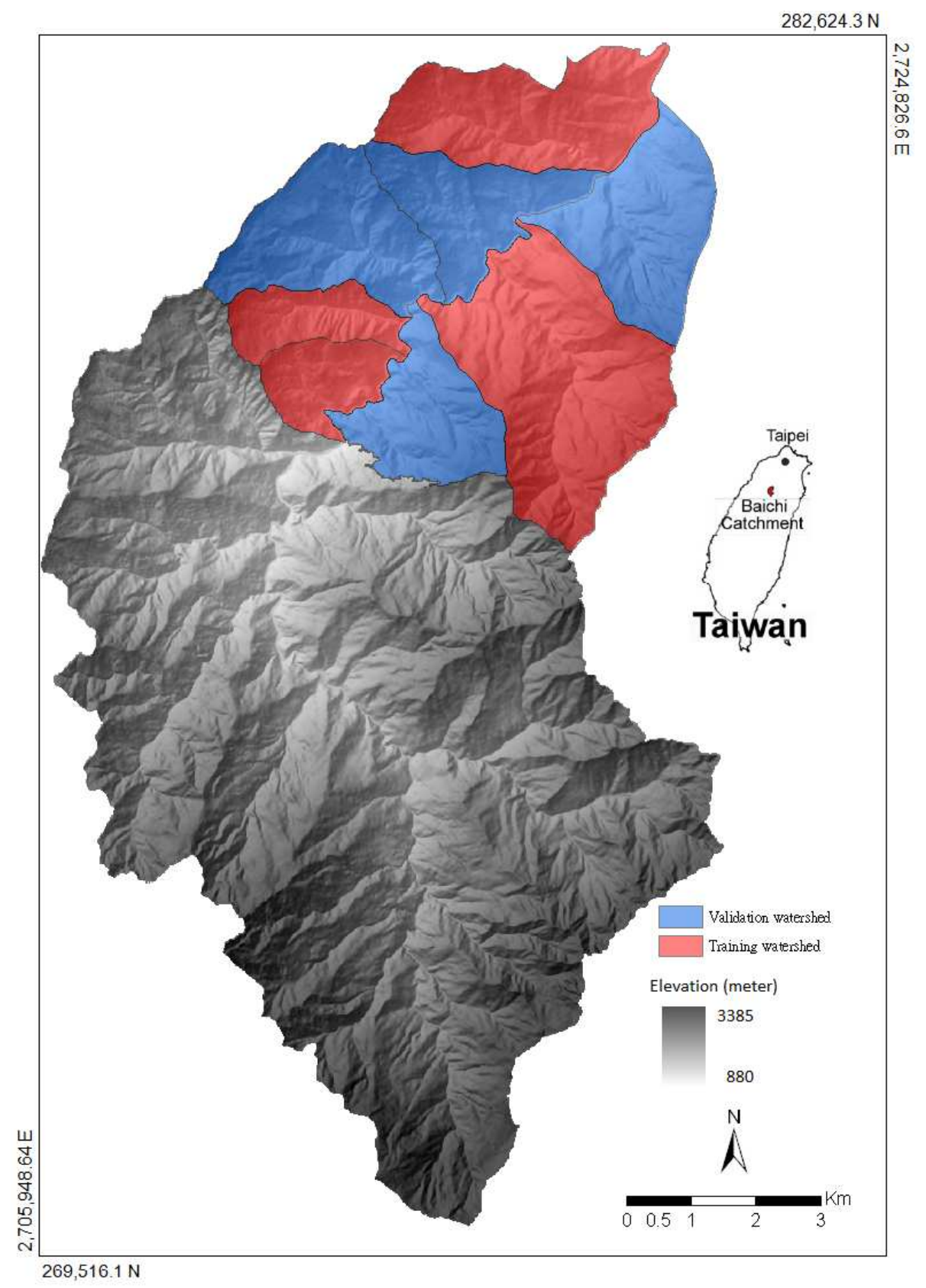

Fig. 1. Study area.

the landslides may have occurred between the September air photo and the November satellite image, which could hinder landslide detection performance assessment. However, we chose this satellite image because it had little cloud interference.

SPOT-5 possesses panchromatic and multispectral sensors, with the nadir spatial resolution of 5 and $10 \mathrm{~m}$, respectively. A $2.5 \mathrm{~m}$ supermode image for the near infrared, the red and the green band satellite images was purchased from the Center for Space and Remote Sensing Research of National Central University, at a level 3 of processing.
Level 3 images have undergone radiometric correction, geometrical correction, ground control point calibration and ortho-rectification. The object-based image analysis of the satellite image was conducted with Definiens Developer, Ell Earth, version 7.0.3.

Finally, we used a $10 \mathrm{~m}$ DTM, compiled from the stereo pairs of 1:5000 aerial photographs. The DTM was prepared by a private contractor for a governmental project in the Shihmen Reservoir watershed. The contractor did not provide data accuracy statistics. We used this DTM because the alternative would have been the official $40 \mathrm{~m}$ DEM, 


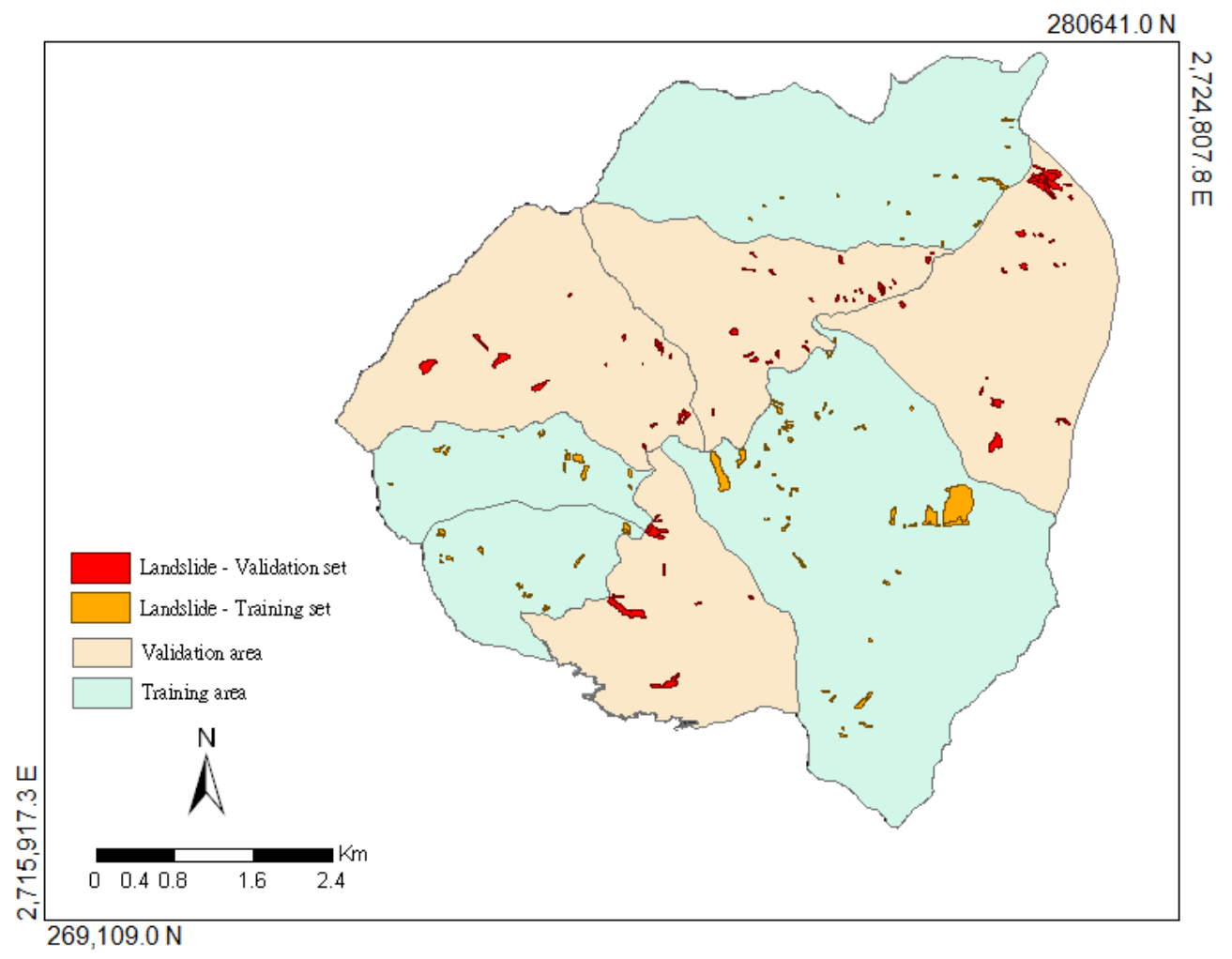

Fig. 2. Landslide inventory from aerial-photograph interpretation.

which was too coarse for geomorphic analysis. The DTM was used in ArcGIS to generate sub-watersheds with the hydrology tool. The DTM was uploaded in Definiens to serve in the classification process.

\section{Methodology}

Applying a multi-scale OBIA to landslide detection involved three methodological steps. We first established the segmentation mechanisms of the satellite image to ensure realworld landslides and the objects obtained from segmentation match. Second, we developed a classification scheme that could correctly identify landslide objects and discard nonlandslide objects. Third, we set up tests to estimate the performance of our technique, to compare its results with single scale classification methods, and to validate against independent landslide information. The overall methodological workflow was summarized in Fig. 3.

\subsection{Multi-scale segmentation for landslides}

In OBIA, segmentation is the first step of an analysis. It partitions the image into objects. These objects can thereafter be characterised and classified. Different multiple segmentation options exist in the literature (Kerle and de Leeuw, 2009). We used the multi-resolution segmentation included in the Definiens software (Bentz et al., 2004; Definiens, 2007b), because it provides the means for multiple segmentation at different scales (Burnett and Blaschke, 2003; Benz et al., 2004; Hay and Castilla, 2008; Lang, 2008).

Analyzing at multiple scales offers better results in objectbased methods (Hay et al., 1997; Baatz and Shäpe, 2000; Hay and Marceau, 2004; Hay et al., 2005), because, often, no single scale can produce objects matching correctly a phenomenon to be analyzed (Hay et al., 2001; Arbiol et al., 2006).

In the case of landslides, Martha et al. (2010) estimated that multi-scale processing, along with post-segmentation merging, was one of the viable options to detect landslides with OBIA. We focused on multi-scaling and classification with appropriate sets of rules and thresholds at each scale rather than post-segmentation merging, because it enabled us to identify landslides objects during the classification process through shape features characterizing the shallow landslides in our training set. We also opted for multi-scaling because of the valuable information which could be derived from the landslide size statistics to define our scales for analysis.

For a given triggering event over a given area, previous studies have found that the probability density of the occurred landslide areas fit a truncated inverse Gamma distribution (Malamud et al., 2004; Guzzetti, 2005). The distribution can be used to predict the size for the most abundant landslides in a watershed and more generally the probability of having landslides of a given size. Although the 


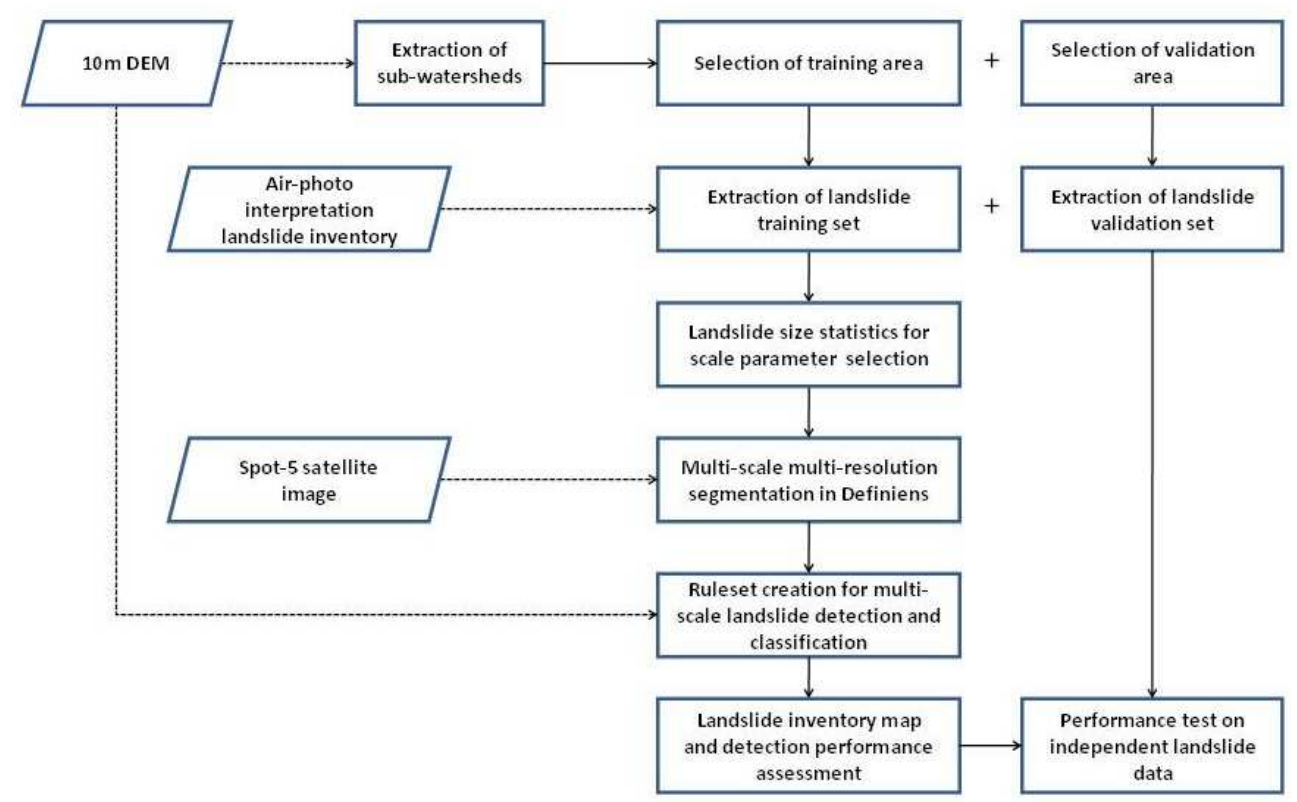

Fig. 3. General methodological workflow.

Table 2. Scale parameters and object size statistics.

\begin{tabular}{lrrrrrrr}
\hline $\begin{array}{l}\text { Scale } \\
\text { parameter }\end{array}$ & 500 & 200 & 100 & 70 & 50 & 30 & 10 \\
\hline Objects $(n)$ & 123 & 743 & 3004 & 6575 & 14157 & 43715 & 415371 \\
Mean $\left(\mathrm{m}^{2}\right)$ & 637454 & 105527 & 26101 & 11925 & 5538 & 1794 & 189 \\
Min $\left(\mathrm{m}^{2}\right)$ & 10361 & 793 & 244 & 69 & 28 & 25 & 6 \\
Max $\left(\mathrm{m}^{2}\right)$ & 6704725 & 770189 & 499178 & 161396 & 63564 & 26062 & 2988 \\
Qu10 $\left(\mathrm{m}^{2}\right)$ & 26940 & 9415 & 3632 & 2158 & 1243 & 440 & 50 \\
Qu20 $\left(\mathrm{m}^{2}\right)$ & 93064 & 21253 & 7185 & 3763 & 2070 & 721 & 78 \\
\hline
\end{tabular}

Qu10 and Qu20 stand for the 10th quantile and the 20th quantile; we listed them because landslides objects are often smaller than the majority of objects.

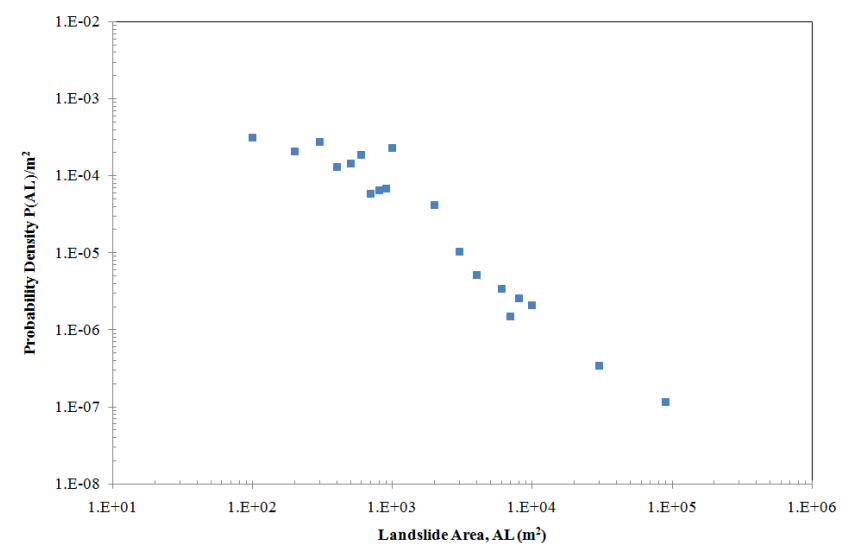

Fig. 4. Probability density of landslide areas from the landslide training set. landslide inventory of the training set was small, its landslide size statistics still provided a base for selecting the array of scales for segmentation. Figure 4 showed that segmentations resulting in objects with sizes ranging from $200 \mathrm{~m}^{2}$ to $90000 \mathrm{~m}^{2}$ were required and that a larger concentration of scales was needed for objects between $200 \mathrm{~m}^{2}$ and $1000 \mathrm{~m}^{2}$ to deal with the higher probability density in this range of areas.

We heuristically selected scales which fitted these requirements in terms of object size and segmented the study area seven times, for scale parameters of 500, 200, 100, 70, 50, 30 and 10 . We named the segmentation levels after the scale parameter they were derived with, i.e. L500, L200, L100, L70, L50, L30, and L10, with L500 having the largest object size and L10 the smallest (Table 2). Our multi-scale segmentation therefore resulted in seven successive object levels on which landslide detection and classification was performed. 


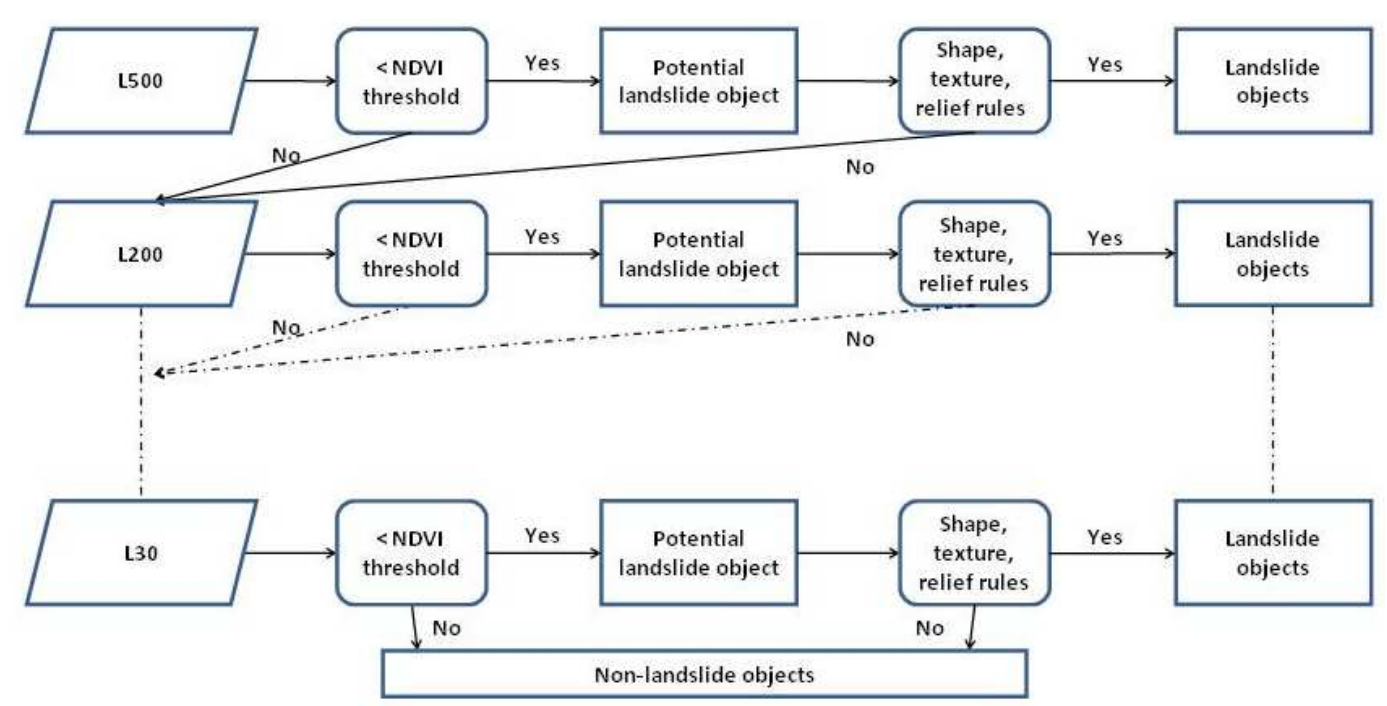

Fig. 5. Classification ruleset flowchart.

Table 3. Features used for ruleset creation.

\begin{tabular}{lll}
\hline & Rule feature & Reference \\
\hline \multirow{2}{*}{ Spectral } & NDVI & Barlow et al. (2003) \\
& Brightness & Moine et al. (2009) \\
Shape & Compactness & Moine et al. (2009) \\
& Length to width & Moine et al. (2009) \\
Texture & GLCM mean of the red band & Martha et al. (2010) \\
& Sub-objects stdev. of mean NDVI & - \\
Relief & Relief to length & (adapted from \\
& Relief to width & Barlow et al., 2006) \\
\hline
\end{tabular}

\subsection{Classification}

In OBIA, once an image is segmented, its objects can be detected and classified through rule set development and application, in our case to obtain a landslide inventory map.

Our classification process relied on a similar set of rules found in previous landslide OBIA research (Martin and Franklin, 2005; Martha et al., 2010) (Table 3). It combined spectral, relief, shape, and texture features to recognize landslide objects and discriminate false positives, as detailed in our rule set flowchart (Fig. 5). The general approach was to first recognize landslide candidates with NDVI (normalized differential vegetation index) and then eliminate false positives, as done in previous research (Martha et al., 2010). Thresholds were obtained interactively by comparing the spectral, relief, shape, and texture feature values of the landslides from the training set with the feature values of the non-landslide objects from the training area (Table 4).

We reproduced this detection and classification approach for each level, starting with L500, and then successively L200, L100, L70, L50 and L30. When an object was detected and classified as a landslide at a given scale, we no longer analyzed its sub-objects when classifying at the next levels. We did not classify at L10, because L10 was only used to generate sub-objects for L30. The need for subobject comes from the texture feature values derived from sub-objects.

In Martha et al. (2010), after a first classification, detected landslide objects were merged and then refined for more homogeneity through a chessboard segmentation, to eliminate from the landslide objects the remaining non-landslide elements. With our multi-scale technique, this result was obtained differently. We relied on a specific texture feature, calculated from the NDVI mean and standard deviation of the sub-objects, to determine its degree of homogeneity. It eliminated objects, which, at a large scale, included both a landslide and other land uses. We relied on this feature to ensure that landslide classification did not occur at a large scale if the object's homogeneity was too low as defined in Table 4.

Finally, the landslides classified at each successive scale were mapped together to obtain a landslide inventory map for the training area.

\subsection{Tests}

Three tests were performed to assess our methodology. First, we determined the detection performance through the modified success rate (MSR) from Huang and Kao (2006). Second, we compared results from our multi-scale approach with the results under single scale approaches. Third, we tested our multi-scale OBIA methodology against independent landslide information, with the landslide set from the validation area. 
Table 4. Detection and classification thresholds.

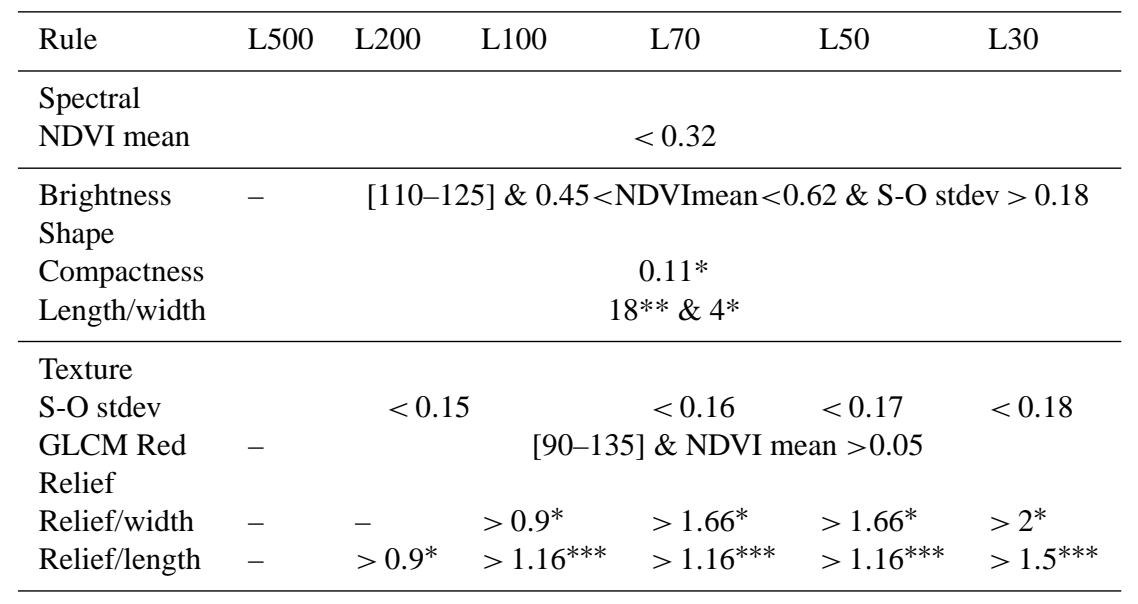

S-O stdev. stands for the NDVI mean standard deviation of sub-objects, while GLCM Red stands for the grey level co-occurrence matrix of the red band. *,**, and $* * *$ indicate that the threshold applies respectively to the polygon, to the skeleton, and to both the polygon and skeleton of the objects. Brightness is used to detect landslides in darker sections of the image.

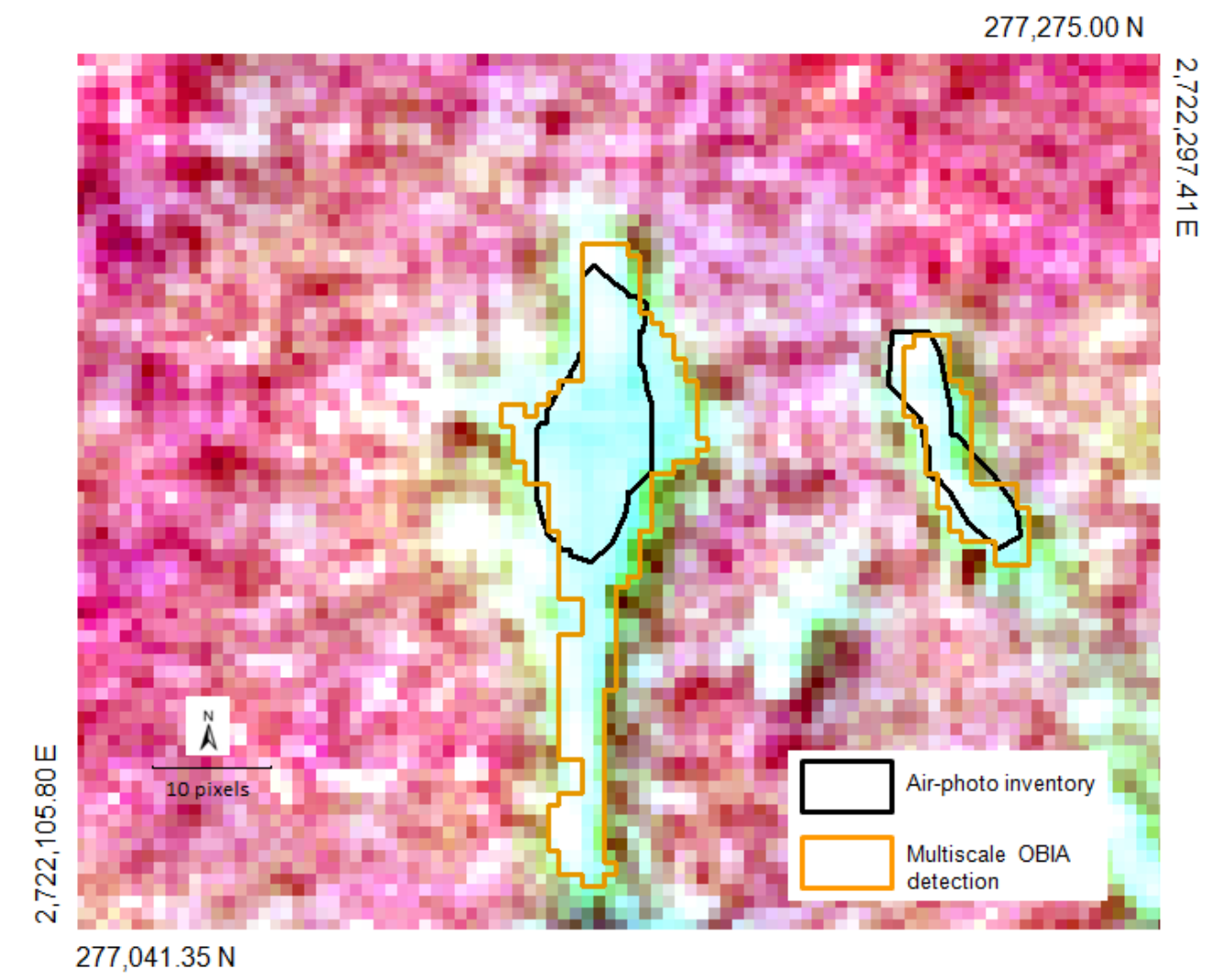

Fig. 6. Comparison of landslide delineation between air-photo inventory and multi-scale OBIA detection.

To assess the landslide detection performance of our methodology, we calculated the MSR, defined as:

$\mathrm{MSR}=0.5\left(\mathrm{SR}_{\text {number }}+\mathrm{SR}_{\text {cells }}\right)$, where $\mathrm{SR}_{\text {number }}$ is the rate of successfully detected landslides [\%] and $\mathrm{SR}_{\text {cell }}$ is the area proportion of successfully detected stable areas [\%]. By having two equally weighted components, MSR considers the detection of both landslide sites and stable areas. For example, if a methodology 
Table 5. MSR for multiscale detection.

\begin{tabular}{lll}
\hline & $\begin{array}{l}\text { Training set } \\
\text { SR }\end{array}$ & $\begin{array}{l}\text { Validation set } \\
(\%)\end{array}$ \\
98.6 & 98.9 \\
\hline SR $_{\text {number }}(\%)$ & 74.2 & 73.1 \\
MSR (\%) & 86.4 & 86.0 \\
\hline
\end{tabular}

Table 6. MSR for single-scale detection.

\begin{tabular}{llllllll}
\hline & L500 & L200 & L100 & L70 & L50 & L30 & SDS \\
\hline SR $_{\text {cell }}$ & 1.00 & 1.00 & 1.00 & 0.99 & 0.99 & 0.99 & 1.00 \\
SR $_{\text {number }}$ & 0.01 & 0.18 & 0.29 & 0.41 & 0.37 & 0.40 & 0.48 \\
MSR & 0.51 & 0.59 & 0.64 & 0.70 & 0.68 & 0.70 & 0.74 \\
\hline
\end{tabular}

SDS stands for the classification scheme obtained after complementing L30 with a spectral difference segmentation.

successfully maps $90 \%$ of landslides and only $50 \%$ of stable areas, its MSR has a value of 0.70 (Chang and Chiang, 2009).

A second test was conducted to compare the detection performance of our multi-scale approach with single scale approaches. We ran a single scale classification for L500, L200, L100, L70, L50 and L30 and compared their detection accuracy to the multi-scale results. In addition, we also ran a classification after improving the scale 30 segmentation with a spectral difference segmentation, and compared again the detection accuracy to the multi-scale results.

The third test consisted in the validation of our methodology by replicating the study with new landslide data in the validation area to assess the performance with independent landslide information.

\section{Results}

The landslide inventory map (Fig. 7) obtained through our multi-scale OBIA approach correctly classified 72 of the 97 landslides in the training area, resulting in an $\mathrm{SR}_{\text {number }}$ of $74 \%$. The methodology correctly classified most stable areas with an $\mathrm{SR}_{\text {cell }}$ of $99 \%$. As a result, the MSR was $86.4 \%$ (Table 5).

Detection performance using single scales instead of the multi-scale methodology resulted in an MSR of $51 \%$ with L500 only, $58 \%$ with L200, $64 \%$ with L100, $71 \%$ with L70, $69 \%$ with L50, and $70 \%$ with L30. When complementing L30 with a spectral difference segmentation, the MSR improved slightly to $74 \%$ (Table 6).

The validation resulted in the correct classification of 68 landslides out of the 93 found in the validation area, for an $\mathrm{SR}_{\text {number }}$ of $73 \%$. The methodology correctly classified most stable areas with an $\mathrm{SR}_{\text {cell }}$ of $99 \%$. With an MSR at $86 \%$,
Table 7. Detection rate by landslide size class.

\begin{tabular}{llllll}
\hline & $\begin{array}{l}\text { Very small } \\
0-20 \%\end{array}$ & $\begin{array}{l}\text { Small } \\
20-40 \%\end{array}$ & $\begin{array}{l}\text { Medium } \\
40-60 \%\end{array}$ & $\begin{array}{l}\text { Large } \\
60-80 \%\end{array}$ & $\begin{array}{l}\text { Very Large } \\
80-100 \%\end{array}$ \\
\hline Detection rate & 0.61 & 0.68 & 0.74 & 0.76 & 0.89 \\
\hline
\end{tabular}

the validation performance was therefore close to the one achieved with the training data set (Table 5).

\section{Discussion}

In this section, we first discuss the performance achieved by our multi-scale OBIA detection technique, before pointing out the limitations inherent to our methodology. Finally, we suggest potential applications.

\subsection{OBIA, multi-scale, and landslide detection performance}

Crucial to the application of satellite remote-sensing to landslide mapping is the need for effective image classification means (Tso and Mather, 2001; Landgrebe, 2003; Lu and

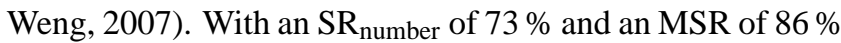
when tested against independent landslide data, our semiautomated multi-scale OBIA detection scheme achieved detection performances in a similar range as the results of other recent studies on landslide mapping with OBIA (Barlow et al., 2006; Lu et al., 2011; Martha et al., 2010, Stumpf and Kerle, 2011a). It achieved acceptable performance levels for landslide susceptibility mapping, as defined in Guzzetti et al. (2006b).

Our multi-scale methodology outperformed all the singlescale classifications, with the best detection performance with single-scale classifications reaching only an $\mathrm{SR}_{\text {number }}$ of $41 \%$ and an MSR of $71 \%$. Recognizing that single-scale classifications may be improved through additional treatment of the results notably through merging and growing algorithms available in Definiens, we complemented L30 with a spectral difference segmentation, and obtained an MSR of $74 \%$, still much lower than the $86 \%$ achieved with the multiscale methodology.

Our multi-scale detection approach performed well for landslides of all sizes. We divided the landslide inventory into 5 classes, based on the landslide size. Our technique detected $61 \%$ of the very small landslides $\left(83-370 \mathrm{~m}^{2}\right)$, $68 \%$ of the small landslides $\left(370-734 \mathrm{~m}^{2}\right), 74 \%$ of the medium landslides $\left(724-1121 \mathrm{~m}^{2}\right), 76 \%$ of the large landslides $\left(1121-2437 \mathrm{~m}^{2}\right)$, and $89 \%$ of the very large landslides (2537-90000 $\mathrm{m}^{2}$ ) (Table 7). It therefore detected a substantial amount of landslides of all sizes, even the smallest landslides. 


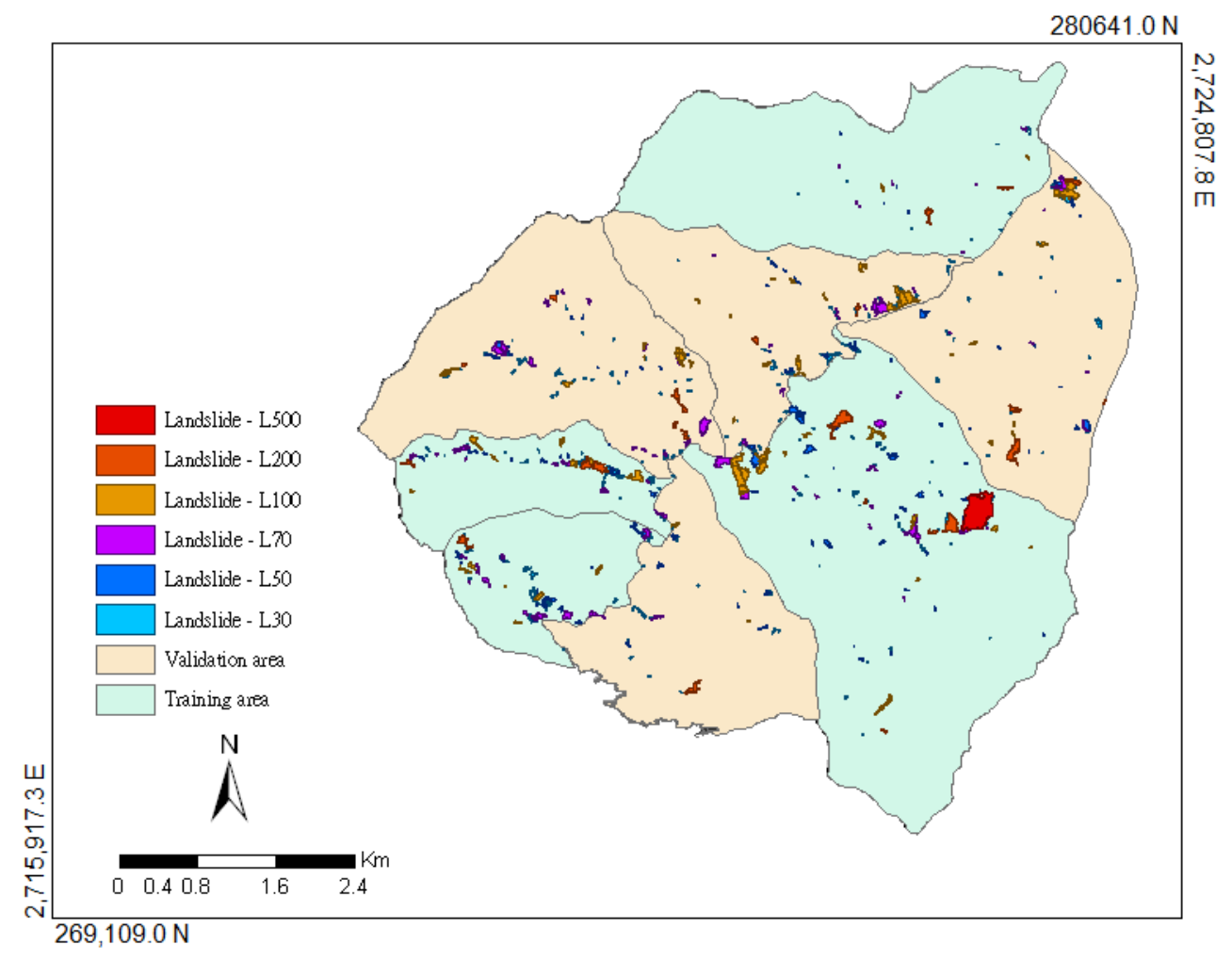

Fig. 7. Landslide inventory map from multi-scale OBIA detection.

Our multi-scale approach differed from Lu et al. (2011), who detected correctly $80 \%$ of the landslides at validation, because their methodology included change detection, i.e. they analyzed the change between two successive satellite images. However, OBIA change detection methodologies might not have been appropriate in our area, because roads frequently change their course to adapt to landslide events, agricultural fields are harvested several times a year, and bamboo forests can be harvested annually and all year-round.

\subsection{Limitations}

Our semi-automated multi-scale OBIA detection scheme had limitations. Although we validated the methodology against independent landslide data in sub-watersheds not included in the training process, the performance results may not hold once applied to map landslides occurring after a different trigger. The detection thresholds were site-specific, since they were determined by the landslide data and the stable objects from the training area. We recognize that automation of threshold detection, such as in Stumpf and Kerle (2011b) and Martha et al. (2011), could mitigate this limitation.

The geographic and geomorphologic proximity between the training area and the validation area may have ensured the constancy of the detection performance at the validation stage. This site-specificity limitation of OBIA classification methods was partly confirmed by the low detection results we achieved when applying the successful rule set from Martha et al. (2010), available online, in our study areas. Besides being site-specific, the thresholds in the ruleset are also image specific, at least for the rules based on spectral features, such as NDVI.

To select our segmentation scales, we relied on landslide size statistics. The analysis of landslide size statistics from Taiwan has shown that in Taiwan, larger landslides contribute more to the total inventory than in other areas in the world (Chen et al., 2007; van den Eeckhaut et al., 2007). In a different context, the range of scales needed may differ.

Also, the inventory contained exclusively shallow slides, which are frequent in Taiwan's mountainous watersheds (Chang and Chiang, 2009). Therefore, it may not work appropriately in regions where other types of slides occur.

\subsection{Potential applications}

Despite the aforementioned limitations, our semi-automated classification scheme still has potential applications to improve landslide mapping for landslide hazard assessment.

With air photo interpretation, experts often need to devote months to complete landslide inventory maps (Liu and Woing, 1999; Galli et al., 2008). When large areas are recurrently struck by typhoons, as is the case in Taiwan (Chiang and Chang, 2011), it may become difficult to actually complete landslide inventory maps relying solely on 
air photo interpretation. Our multi-scale OBIA classification can complement the interpretation of air photos in these situations.

While we recognize that we did not assess the robustness and sensitivity of our technique to variation in input data, we observe that with half of the landslide information for a given watershed, we were able to design a semi-automated classification with similar performance in training and validation. The current multi-scale segmentation can, in theory, detect slides as large as $3 \mathrm{~km}^{2}$ based on the maximal object size with the largest scale.

Also, updating the classification thresholds simply involves comparing feature value statistics for known landslides and known stable objects. In Definiens, these statistics can be calculated in a few minutes. The time for segmentation and classification in our case study did not go over half an hour. We therefore suggest that our semi-automated detection method could, with the necessary adaptations, potentially serve to speed up the air-photo mapping process in case large areas are affected by shallow landslides.

\section{Conclusions}

We developed a multi-scale OBIA landslide detection technique to map landslides in the Baichi watershed, Taiwan, after the 2004 Typhoon Aere event. Our semi-automated detection method consisted in successive classification rounds at multiple scales. The detection performance achieved an MSR of $86.5 \%$ with the training dataset and $86 \%$ with the validation dataset. This performance level was due to the multi-scale aspect of our methodology, as MSR for single scale classification ranged between $51 \%$ for L500 and $71 \%$ for L70. Our multi-scale technique proved that it could detect a substantial amount of landslides of all sizes, including very small landslides. The methodology developed presented certain limitations: the thresholds we established for classification were specific to the area, to the landslide type in the study area, and to the spectral characteristics of the satellite image. However, updating site-specific and image-specific classification thresholds is trivial with Definiens. Our multiscale OBIA detection technique could thus prove useful for mapping shallow landslides in large areas.

Acknowledgements. This study was supported by a grant from Taiwan's National Science Council (100-2410-H-424-018-). We are grateful to the two anonymous reviewers for the constructive reviews and useful suggestions. We thank Sinotech Engineering Consults Inc. for the provision of satellite images and Lin MinLang for kindly sharing his software.

Edited by: A. Günther

Reviewed by: two anonymous referees

\section{References}

Arbiol, R., Zhang, Y., and Palà, V.: Advanced classification techniques: a review, ISPRS Commission VII Mid-term Symposium "From Pixel to Processes", Enschede, Netherlands, 8-11 May 2006, 2006.

Baatz, M. and Schäpe, M.: Multiresolution segmentation - An optimization approach for high quality multi-scale image segmentation, in: Angewandte Geographische Informations-Verarbeitung XII, edited by: Strobl, J., Blaschke, T., and Griesebner, G., Wichmann Verlag, Karlsruhe, Germany, 12-23, 2000.

Barlow, J., Martin, Y., and Franklin, S. E.: Detecting translational landslide scars using segmentation of Landsat ETM+ and DEM data in the northern Cascade Mountains, British Columbia, Can. J. Remote Sens., 29, 510-517, 2003.

Barlow, J., Franklin, S., and Martin, Y.: High spatial resolution satellite imagery, DEM derivatives, and image segmentation for the detection of mass wasting processes, Photogramm. Eng. Rem. S., 72(6), 687-692, 2006.

Benz, U. C., Hofmann, P., Willhauck, G., Lingenfelder, I., and Heynen, M.: Multiresolution, object-oriented fuzzy analysis of remote sensing data for GIS-ready information, ISPRS J. Photogramm., 58, 239-258, 2004.

Blaschke, T.: Object based image analysis for remote sensing, ISPRS J. Photogramm., 65, 2-16, 2010.

Blaschke, T. and Hay, G. J.: Object-oriented image analysis and scale-space: Theory and methods for modeling and evaluating multi-scale landscape structure, in: International Archives of Photogrammetry and Remote Sensing 34 (Part 4/W5), Athens, Georgia, USA, 29-31 October 2001, 22-29, 2001.

Burnett, C. and Blaschke, T.: A multi-scale segmentation/object relationship modeling methodology for landscape analysis, Ecol. Model., 168(3), 233-249, 2003.

Chang, K. T. and Chiang, S. H.: An integrated model for predicting rainfall-induced landslides, Geomorphology, 105, 366-373, 2009.

Chen, C. Y., Yu, F. C., Lin, S. C., and Chuenh, K. W.: Discussion of landslide self-organized criticality and the initiation of debris flow, Earth Surf. Proc. Land., 32, 197-209, 2007.

Cheng, C., Hsu, N., and Wei, C.: Decision-tree analysis on optimal release of reservoir storage under typhoon warnings, Nat. Hazards, 44, 65-84, 2008.

Chiang, S. H. and Chang, K. T.: Application of radar data to modeling rainfall-induced landslides, Geomorphology, 103, 299-309, 2009.

Chiang, S. H. and Chang, K. T.: The potential impact of climate change on typhoon-triggered landslides in Taiwan, 2010-2099, Geomorphology, doi:10.1016/j.geomorph.2010.12.028, 2011.

Chiu, Y. J., Borghuis, A. M., Lee, H. Y., Chang, K. T., and Chao, J. H.: Estimation of soil erosion in a reservoir watershed using $\sim(137)$ CS fallout radionuclide, Int. J. Sediment Res., 4, 304317, 2007.

Definiens: Developer 7: Reference Book, Definiens Imaging $\mathrm{GmbH}, 2007 \mathrm{a}$.

Definiens: Developer 7: Userguide, Definiens Imaging $\mathrm{GmbH}$, 2007b.

Dragut, L., Tiede, D., and Levick, S. R.: ESP: a tool to estimate scale parameter for multiresolution segmentation of remotely sensed data, Int. J. Geogr. Inf. Sci., 24, 859-871, 2010.

Galli, M., Ardizzone, F., Cardinali, M., Guzzetti, F., and Reichen- 
bach, P.: Comparing landslide inventory maps, Geomorphology, 94, 268-289, 2008.

Gitas, I. Z., Mitri, G. H., and Ventura, G.: Object-based image classification for burned area mapping of Creus Cape, Spain, Remote Sens. Environ., 92, 709-713, 2003.

Guzzetti, F.: Landslide Hazard and Risk Assessment Concepts, Ph.D. thesis, Faculty Faculty of Mathematics and Natural Sciences, Bonn University, Germany, 371 pp., 2005.

Guzzetti, F., Carrara, A., Cardinali, M., and Reichenbach, P.: Landslide hazard evaluation: a review of current techniques and their application in a multi-scale study, Central Italy, Geomorphology, 31, 181-216, 1999.

Guzzetti, F., Cardinali, M., Reichenbach, P., and Carrara, A.: Comparing landslide maps: a case study in the upper Tiber River Basin, Central Italy, Environ. Manage., 25, 247-363, 2000.

Guzzetti, F., Galli, M., Reichenbach, P., Ardizzone, F., and Cardinali, M.: Landslide hazard assessment in the Collazzone area, Umbria, Central Italy, Nat. Hazards Earth Syst. Sci., 6, 115-131, doi:10.5194/nhess-6-115-2006, 2006a.

Guzzetti, F., Reichenbach, P., Ardizzone, F., Cardinali, M., and Galli, M.: Estimating the quality of landslide susceptibility models, Geomorphology, 81, 166-184, 2006 b.

Hansen, A.: Landslide hazard analysis, in: Slope Instability, edited by: Brunsden, D. and Prior, D. B., John Wiley, New York, USA, 523-602, 1984.

Hay, G. J. and Castilla, G.: Geographic object-based image analysis (GEOBIA): a new name for a new discipline, in: Object Based Image Analysis, Blaschke, T., Lang, S., and Hay, G., Springer, Heidelberg, Berlin, New York, 93-112, 2008.

Hay, G. J. and Marceau, D. J.: Multiscale object-specific analysis (MOSA): an integrative approach for multiscale landscape analysis, in: Remote Sensing and Digital Image Analysis. Book Series: Remote Sensing and Digital Image Processing, vol. 5, de Jong, S. M. and van der Meer, F. D., Kluwer Academic Publishers, Dordrecht, Netherlands, 71-92, 2004.

Hay, G., Niemann, K., and Goodenough, D.: Spatial thresholds, image-objects, and upscaling: a multiscale evaluation, Remote Sens. Environ., 62, 1-19, 1997.

Hay, G. J., Marceau, D. J., Dube, P., and Bouchard, A.: A multiscale framework for landscape analysis: object-specific analysis and upscaling, Landscape Ecol., 16, 471-490, 2001.

Huang, J. C. and Kao, S. J.: Interactive comment on "Optimal estimator for assessing landslide model efficiency", Hydrol. Earth Syst. Sci. Discuss., 3, S669-S673, 2006.

Kerle, N. and de Leeuw, J.: Reviving legacy population maps with object-oriented image processing techniques, IEEE T. Geosci. Remote, 47, 2392-2402, 2009.

Kim, M., Madden, M., and Warner, T.: Estimation of optimal image object size for the segmentation of forest stands with multispectral IKONOS imagery, in: Object-based image analysis spatial concepts for knowledge driven remote sensing applications, edited by: Blaschke, T., Lang, S., and Hay, G. J., Springer, Berlin, Germany, 291-307, 2008.

Landgrebe, D. A.: Signal Theory Methods in Multispectral Remote Sensing, John Wiley and Sons, Hoboken, New Jersey, USA, 2003.

Lang, S.: Object-based image analysis for remote sensing applications: modeling reality - dealing with complexity, in: Objectbased image analysis - spatial concepts for knowledge driven remote sensing applications, edited by: Blaschke, T., Lang, S., and Hay, G. J., Springer, Berlin, Germany, 1-25, 2008.

Liu, J. and Woing, T.: A practical approach to creating a landslide database using Taiwan SPOT mosaic, in Proceedings of the 20th Asian Conference on Remote Sensing (ACRS 1999), Hong Kong, China, 22-25 November 1999, electronic proceedings, 1999.

Lu, D. and Weng, Q.: A survey of image classification methods and techniques for improving classification performance, Int. J Remote Sens., 28, 823-870, 2007.

Lu, P., Stumpf, A., Kerle, N., and Casagli, N.: Object-oriented change detection for landslide rapid mapping, IEEE Geosci. Remote S., 8, 701-705, doi:10.1109/LGRS.2010.2101045, 2011.

Malamud, B. D., Turcotte D. L., Guzzetti, F., and Reichenbach, P.: Landslide inventories and their statistical properties, Earth Surf. Proc. Land., 29, 687-711, 2004.

Martha, T. R., Kerle, N., Jetten, V., van Westen, C. J., and Kumar, K. V.: Characterising spectral, spatial and morphometric properties of landslides for semi-automatic detection using object-oriented methods, Geomorphology, 116, 24-36, 2010.

Martha, T. R., Kerle, N., van Westen, C., Jetten, V., and Kumranchat, V. K.: Segment optimisation and data-driven thresholding for knowledge-based landslide detection by objectbased image analysis, IEEE T. Geosci. Remote, 99, 1-16, doi:10.1109/TGRS.2011.2151866, 2011.

Martin, Y. E. and Franklin, S. E.: Classification of soil- and bedrock-dominated landslides in British Columbia using segmentation of satellite imagery and DEM data, Int. J. Remote Sens., 26, 1505-1509, 2005.

Moine, M., Puissant, A., and Malet, J. P.: Detection of landslides from aerial and satellite images with a semi-automatic method. Application to the Barcelonnette basin (Alpes-deHaute-Provence, France), in: Landslide Processes: From Geomorphological Mapping to Dynamic Modelling, Malet, J. P., Remaitre, A., and Bogaard, T., CERG, Strasbourg, France, 63-68, 2009.

Park, N. W. and Chi, K. H.: Quantitative assessment of landslide susceptibility using high-resolution remote sensing data and a generalized additive model, Int. J. Remote Sens., 29, 247-264, 2008.

Rau, J., Chen, L., Liu, J., and Wu, T.: Dynamics monitoring and disaster assessment for watershed management using time-series satellite images, IEEE T. Geosci. Remote, 45, 1641-1649, 2007.

Stumpf, A. and Kerle, N.: Combining Random Forests and objectoriented analysis for landslide mapping from very high resolution imagery, Procedia Environmental Sciences, 3, 14-129, 2011a.

Stumpf, A. and Kerle, N.: Object-oriented mapping of landslides using Random Forests, Remote Sens. Environ., in press, doi:10.1016/j.rse.2011.05.013, 2011 b.

Thomas, N., Hendrix, C., and Congalton, R. G.: A comparison of urban mapping methods using high-resolution digital imagery, Photogramm. Eng. Rem. S., 69, 963-972, 2003.

Tso, B. and Mather, P. M.: Classification Methods for Remotely Sensed Data, Taylor and Francis, New York, USA, 2001.

van den Eeckhaut, M., Poesen, J., Govers, G., Verstaeten, G., and Demoulin, A.: Characteristics of the size distribution of recent and historical landslides in a populated hilly region, Earth Planet.Sc. Lett. 256, 588-603, 2007. 
van Westen, C. J., Castellanos, E., and Kuriakose, S. L.: Spatial data for landslide susceptibility, hazard, and vulnerability assessment: an overview, Eng. Geol., 102, 112-131, 2008.

Varnes, D. J. and IAEG Commission on Landslides and other MassMovements: Landslide hazard zonation: a review of principles and practice, UNESCO Press, Paris, France, 1984.

Walter, V.: Object-based classification of remote sensing data for change detection, ISPRS J. Photogramm., 58, 225-238, 2004.
Zhou, W. and Troy, A.: An object-oriented approach for analysing and characterizing urban landscape at the parcel level, Int. J. Remote Sens., 29, 3119-3135, 2008.

Zhou, W., Troy, A., and Grove, M.: Modeling residential lawn fertilization practices: integrating high resolution remote sensing with socioeconomic data, Environ. Manage., 41, 742-752, 2008. 